\title{
CS@Mines Successful S-STEM Scholarship Ecosystem for Low-Income and Underrepresented Students
}

\author{
Tracy Camp \\ tcamp@mines.edu \\ Colorado School of Mines
}

\author{
Christine Liebe \\ cliebe@mines.edu \\ Colorado School of Mines
}

\author{
Heather Thiry \\ heather.thiry@colorado.edu \\ Golden Evaluation \& Policy Research
}

\begin{abstract}
The primary purpose of PATHS (Path Ambassadors to High Success), an NSF-funded S-STEM scholarship program, is to create new pathways and strengthen existing pathways for academically talented, low-income Colorado high school and community college students to study computer science (CS) at Colorado School of Mines (Mines). PATHS has achieved the following major project goals: 1) Increase number of academically talented, low-income students studying CS in Colorado; 4) Increase retention of these students; 3) Establish an active on-campus community to support PATHS scholars and similar students; 4) Engage scholars to perform CS recruitment and outreach at area high schools and community colleges; 5) Evaluate PATHS activities through comparative analysis to provide new insights on best practices for attracting and retaining academically talented, low-income CS students; 6) Broaden participation of historically underrepresented groups in CS; and 7) Develop a new flexible degree program combining other STEM fields and CS. PATHS students are diverse (e.g., 40.8\% from underrepresented groups in computing) and academically successful (e.g., mean GPA is 3.4). Thus far, the program has awarded scholarships to 49 students and retained $93.9 \%$ of the students. Of the 49 students, six have graduated and three of the six have also pursued a CS Master's degree.
\end{abstract}

\section{CCS CONCEPTS}

-Social and professional topics $\rightarrow$ Computing education programs.

\section{KEYWORDS}

scholarship programs, first generation, low-income, broadening participation, computing education, women, underrepresented groups

\section{ACM Reference Format:}

Tracy Camp, Christine Liebe, and Heather Thiry. 2021. CS@Mines Successful S-STEM Scholarship Ecosystem for Low-Income and Underrepresented Students. In Proceedings of the 52nd ACM Technical Symposium on Computer Science Education (SIGCSE '21), March 13-20, 2021, Virtual Event, USA. ACM, New York, NY, USA, 7 pages. https://doi.org/10.1145/3408877.3432524

Permission to make digital or hard copies of all or part of this work for personal or classroom use is granted without fee provided that copies are not made or distributed for profit or commercial advantage and that copies bear this notice and the full citation on the first page. Copyrights for components of this work owned by others than ACM must be honored. Abstracting with credit is permitted. To copy otherwise, or republish, to post on servers or to redistribute to lists, requires prior specific permission and/or a fee. Request permissions from permissions@acm.org.

SIGCSE '21, March 13-20, 2021, Virtual Event, USA

(C) 2021 Association for Computing Machinery.

ACM ISBN 978-1-4503-8062-1/21/03 . \$ \$15.00

https://doi.org/10.1145/3408877.3432524

\section{OVERVIEW AND CONTEXT}

The Path Ambassadors to High Success (PATHS) S-STEM scholarship program, which is funded by the National Science Foundation (NSF), is a successful model of a research-based undergraduate community that provides academic and community supports for lowincome undergraduates majoring or minoring in Computer Science (CS). Since 2017, PATHS has recruited over 300 low-income students and enrolled 49 at Colorado School of Mines (Mines). PATHS students are diverse (28.6\% female, $40.8 \%$ underrepresented students in computing, and $36.7 \%$ first generation) and academically successful (mean GPA is 3.4 and $38 \%$ have GPAs of 3.5 or higher). In addition, PATHS retention rate is high (93.9\%). We define underrepresented students, or students from underrepresented groups (URGs), in computing in alignment with NSF, e.g., women, African Americans, Hispanics, American Indians, Alaska Natives, Native Hawaiians, Native Pacific Islanders, and persons with disabilities [15, 19, 25].

Analyses of our program successes underscore the importance of developing social capital, community, and a sense of belonging. PATHS leverages an ecosystem of existing university supports, innovative student-led initiatives, K-14 outreach and recruitment, and service learning. PATHS activities, see Figure 1, culminate in the graduation and employment of diverse CS professionals with practiced soft skills, leadership abilities, knowledge of research, and the ability to compassionately mentor others.

\subsection{Positively Impacting Diversity}

PATHS offers a model for increasing the number of highly-skilled diverse CS professionals. The need for STEM professionals is expected to grow $18.4 \%$ between 2020 and 2024, more than all other professions, requiring twice as many computer scientists as engineers [18]. There is an urgent need for computer scientists and engineers with CS skills and knowledge [20,30]. Additionally, STEM professionals versed in CS will likely be in high demand if global outsourcing (e.g., tech workers in India) breaks down and nations rely more on regional economies, such as trading partnerships between the U.S., Canada, and Mexico [13]. PATHS scholars must either (1) major in CS or (2) major in another STEM field and minor in CS.

The evolving flexible CS degree program, now with six tracks (General, Data Science, Business, Robotics and Intelligent Systems, Computer Engineering, and Research Honors), is another aspect that accommodates a broader range of PATHS applicants. The six tracks within the CS degree program are referred to as CS+X tracks, where $\mathrm{X}$ is another STEM discipline. The structure recognizes the wide application of CS and invites students to combine their CS education with another discipline of their choice. We note that PATHS scholars are helping to broaden the participation of historically underrepresented groups in computing at Mines. Specifically, 10 years ago, CS@Mines had 7.6\% students from underrepresented groups 


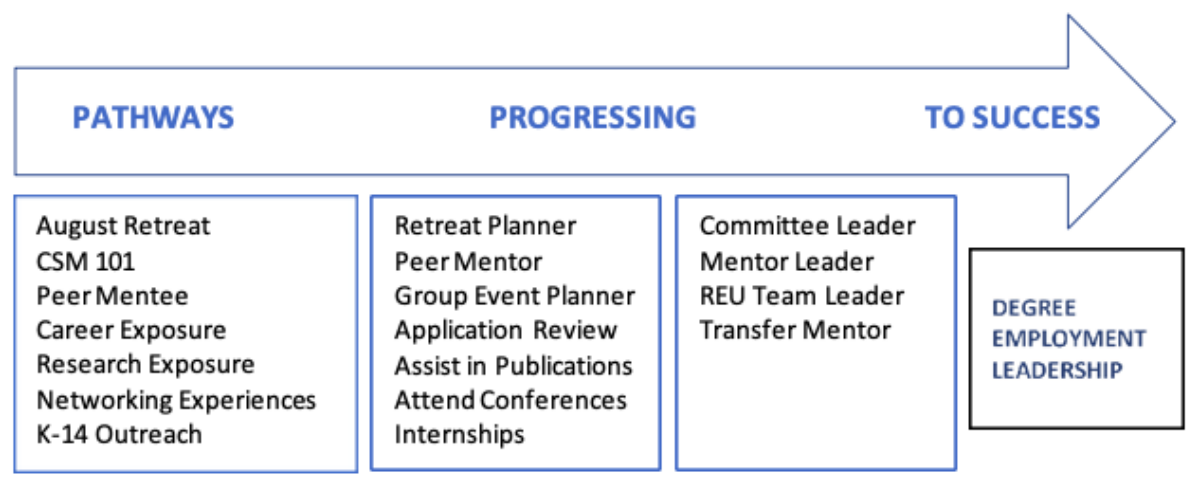

Figure 1: PATHS Progression of Activities

and, today, CS@Mines has 21.5\% (almost triple). These scholars will, ultimately, help diversity our computing workforce.

\subsection{Studying Computing at a Small Rigorous Engineering University}

Mines is a rigorous engineering/science university with selective enrollment requirements. Mines graduates are highly sought after by industry; for example, among 2019 Mines graduates, 95\% were either hired directly out of college (making on average \$73K) or attended graduate school. Sadly, Mines struggles with a) retention of low-income students, b) recruitment of female students and students from other URGs in computing, and c) retention of URG students. For example, only $30.7 \%$ of all students at Mines are female. Mines accepts enough women and students from URGs to potentially achieve a student body with $40 \%$ women and $30 \%$ URGs. Unfortunately, many of these students choose not to enroll. Additionally, retention from year one to year two for Hispanic and low-income Pell grant eligible students lags behind white students and students who are not Pell-eligible, as does four-year degree completion. The PATHS program has provided 14/49 women and 20/49 URG students with scholarships and a supportive ecosystem in which to thrive, consequently impacting university-wide diversity, recruitment, and retention efforts.

Many Mines students have great financial need. PATHS had 169 applicants apply to join the 2020-21 cohort of approximately 20 students. Seventy-five of the 169 applicants were eligible for Pell grants and 59 of these Pell eligible students had unmet financial need of $\$ 5,000$ or more. PATHS scholars receive up to $\$ 10,000$ per year for four years with an average award of $\$ 4,700$. As is typical, Mines defines financial need for undergraduates as the Cost of Attendance (COA) for first year students living on campus, which is currently $\$ 36,693$ for Colorado residents, minus the Estimated Family Contribution (EFC) for the student (as defined by FAFSA). COA for students living off-campus is $\$ 33,828$ for Colorado residents. Mines defines low-income as $150 \%$ of Pell eligible. By requiring PATHS scholars to be residents of Colorado (which means lower cost for tuition), we allocate scholarship funds prudently. Students must re-apply for the scholarship yearly, which also helps to reinforce their responsibilities to the program. A student who joins
PATHS will continue to be funded each year through graduation, assuming program requirements are met and funding is available.

PATHS provides financial support for academically talented students who face financial and socialization struggles common to low-income and first generation college students [11, 14]. PATHS results verify the importance of creating a pathway of personal connection and community from high school to career for lowincome students. PATHS results were presented as a poster at the 2019 NSF S-STEM conference [33] where, because of our program's success, a Mines' PATHS Scholar was invited to speak on a student panel with five other S-STEM scholars from around the country; this panel occurred during a session attended by representatives from all S-STEM programs (300+ people).

\section{METHODOLOGY AND RESULTS}

External evaluation, conducted by Heather Thiry, focuses on the following research questions and consists of annual surveys requesting both Likert-style and open-ended responses. Results were analyzed applying descriptive statistics and domain analysis.

\subsection{Research Questions}

- How has the PATHS program influenced PATHS scholars' academic pathways and progress?

- How has the PATHS program influenced scholars' preparation for careers or graduate school?

- Has the PATHS program impacted scholars' knowledge of campus resources?

- Has the PATHS scholars program fostered a sense of support for participants?

The following results from 2018-19 and 2019-20 describe PATHS scholars' experiences of academic, professional, and supportive program activities. See Table 1 for PATHS recruitment and retention data. We note that students who continued to M.S. program are not counted in Graduated column.

\subsection{Academic and Professional Success}

Overall, PATHS students excel academically; six have graduated, three have continued with graduate studies, and only three have dropped below the required 2.75 GPA. As mentioned previously, the 
Table 1: PATHS: Recruitment and Retention Data

\begin{tabular}{llllll}
\hline Cohort & All scholars & New scholars & Graduated & Left & Continued \\
\hline $2017-2018$ & 6 & 6 & 0 & 1 & 5 \\
$2018-2019$ & 16 & 11 & 3 & 0 & 13 \\
$2019-2020$ & 26 & 13 & 2 & 2 & 22 \\
$2020-2021$ & 41 & 19 & n/a & n/a & n/a \\
\hline Program Totals & & $\mathbf{4 9}$ & $\mathbf{5}$ & $\mathbf{3}$ &
\end{tabular}

average student GPA is 3.4 and $38 \%$ of PATHS scholars have a GPA of 3.5 or higher. Thanks to support structures in the PATHS program, two of the three students who struggled academically during their first year improved significantly (e.g., one GPA improved from 1.2 (F18) to 2.7 (S19) to 3.0 (F19) to 4.0 (S20)). In addition, the majority of students, $90.9 \%$, are on track to graduate in four years. Thus far, six students have obtained their B.S. degree in CS and one has also completed an M.S. degree in CS.

PATHS program activities encourage professional and academic development. PATHS scholars have secured internships at the FBI, Lockheed Martin, Home Advisor, GoGo Air, and more. PATHS graduates work at Tyler Technologies, Woodridge Software, Apple, and Workday. In the following sections, we detail several factors that influence PATHS student success.

\subsection{Nurturing Belonging and Career Pathways}

The primary benefit scholars reported they received from the program was a sense of belonging. Belonging begins for new scholars at the annual summer retreat, which is attended by new and returning scholars. Ninety-three percent of PATHS scholars found the annual two-day retreat held in August 2019 as "valuable" or "very valuable" in fostering connections among fellow scholarship recipients. Scholars reported that supports, such as peer mentoring and regular academic advising, helped them lower stress and perform better academically. Scholars ( $82 \%)$ shared they benefited from learning how to navigate through college in their cohort first year seminar, prepare resumes, obtain internships, and eventually gain employment. The complete PATHS pathway to STEM success, embedded in community and personal connection, is a replicable model.

The three most important benefits PATHS scholars reported receiving (from the 2018-19 external evaluation) follow. (The percentages are the percent of PATHS scholars who mentioned that benefit as being important.) 1) Funding/financial scholarship (100\%); 2) Increased sense of belonging in computer science (92\%); and 3) Guidance on professional development opportunities (92\%). Students were also interested in conducting outreach, particularly the opportunity to broaden participation in computer science through their outreach activities. Nearly all PATHS scholars felt prepared for college-level coursework in their transition to college and felt they had few, to no, academic concerns. As a result of the annual retreat, mentoring community events, and the mid-term faculty advising, 2019-20 PATHS scholars reported [29]:

- $100 \%$ of PATHS scholars felt supported by their PATHS peers

- $85 \%$ of PATHS scholars felt a sense of support from other peers in the CS@Mines department
- $100 \%$ of PATHS scholars felt "strongly" supported by PATHS program administrator

- $85 \%$ of PATHS scholars felt supported by CS faculty

- $92 \%$ of PATHS scholars found the outreach activities to be valuable to their experience in CS@Mines

Without the PATHS scholarships and wrap-around support that our S-STEM grant provided, 19 of the 49 scholars would have likely dropped out of college [12].

\subsection{Comparisons with National Cohorts}

In addition to surveys deployed by the project external evaluator, PATHS scholars complete a national survey for computing students, i.e., the Data Buddies Survey, which is facilitated by the Computing Research Association's (CRA) Center for Evaluating the Research Pipeline (CERP) [32]. Responses from PATHS scholars were compared to a similar group of undergraduates in the United States and Canada $(n=2,017)$. Selection criteria for the students in the comparison group follow:

- attend an institution similar to Mines (i.e., doctoral granting institutions)

- are U.S. citizens

- have parents whose highest education was no higher than the Master's level

- report a socioeconomic status similar to PATHS scholars

- have never considered changing their major

- plan to earn at least a Bachelor's degree as their highest intended degree

- expect to graduate between 2018 and 2022, and

- are either a declared computer science major or intent to major in computer science.

Of the 16 PATHS students who responded to the survey in spring 2018, PATHS scholars, when compared to the comparison group, reported statistically significant greater:

- Positive attitudes towards computing,

- Growth mindset (e.g., computing can be learned),

- Positive attitudes about the computing department,

- Confidence to learn computing,

- Confidence to complete an undergraduate degree,

- Support from mentors and peers,

- Engagement in K-12 outreach, and

- Engagement in computing-related student groups.

PATHS scholars reported that they saw computing as a path of service and planned to pursue graduate degrees in computingrelated fields. That is, PATHS scholars reported greater agreement (mean 4.50, SD(0.63)) than the national cohort (mean 3.65, SD(1.00)) 
with the statement that a career in computing would allow them to serve humanity. The majority of PATHS scholars (67\%) also reported they planned to pursue a Master's degree, which was more than the national comparison group (45\%).

\section{NEW PATHWAYS: RECRUITMENT}

\subsection{Application Process}

PATHS successful recruitment efforts can be attributed to making the application process streamlined with the admission process and K-14 outreach that PATHS scholars conduct as CS@Mines ambassadors. For example, there were 70 applicants for the program in 2018, before we streamlined the application process with Admissions, and 169 applicants for the program in 2019.

PATHS scholars shared information about PATHS with their alma mater high school (HS) counselling offices, connected with AP/IB STEM teachers who recommended recruits, and, in some cases, pitched PATHS directly to students in higher level HS math classes. These efforts are worthwhile, e.g., 62\% of 2018-19 applicants to the program identified a current scholar as influential in their decision to apply to the PATHS scholarship program [28]. Staff in Mines Admissions and Financial Aid also steered high-potential prospects to the PATHS website and encouraged them to apply, as did representatives from the Colorado Education Initiative, Red Rocks Community College "RISE" Program, and the Colorado Council on High School/College Relations (via high school counselor networks).

Admitted students to Mines who list CS as an expressed area of interest for a major (or Mechanical Engineering with "robotics" or "robot" mentioned in their undergraduate application) and who meet the remaining PATHS eligibility criteria (e.g., Colorado resident, FAFSA filed, etc.) receive an email alerting them of the opportunity to apply to PATHS. Each standardized form submitted by admitted students is retained by Admissions in existing software and shared with administrators of relevant programs, including PATHS. Students admitted to Mines for 2019-20 now have one streamlined scholarship application process that covers all scholarships for which they are eligible.

\subsection{K-14 Outreach}

PATHS scholars provide K-14 outreach based on their interests (e.g., visiting their previous high school or providing K-12 CS presentations), in order to offer valuable connections for students interested in CS@Mines. K-14 outreach has proven to aid the development of self-efficacy, retention, and recruitment for first-generation, lowincome, STEM students [9]. When self-efficacy, identity, and values were engaged, undergraduate underrepresented students who enrolled as science majors persisted through to graduation and into their careers four years after graduation [10]. Our established K14 outreach programs are proven effective methods for recruiting low-income scholarship applicants to CS@Mines.

Through several K-12 activities (e.g., CS@Mines On Tour, CSTART), the department has fostered a wide network of K-12 community members in Colorado. For example, five K-12 teachers who attended CS professional development at Mines wrote letters of recommendation for 2020 PATHS applicants. In addition to other efforts (e.g., PATHS scholars staffed a Mines table at "JeffCON", a tech conference hosted by Colorado's second largest public-school district and attended by 600 students), scholars visited their alma mater high school and other neighboring high schools with high percentages of qualified free/reduced lunch students to market PATHS. K-14 outreach (a professional development activity for PATHS scholars) exposes younger students and community college students to engineering and CS. K-14 outreach efforts help to attract academically talented students, especially women and URG students, with financial need. PATHS retains and supports these vulnerable students with financial need through to degree completion, thereby helping to create a more diverse workforce with CS skills.

While K-14 outreach provides scholars with an opportunity to improve professional communication and presentation skills, service learning and CS presentations to K-12 students help them build confidence and develop their identity as knowledgeable and successful in CS. In this regard, K-14 outreach serves dual purposes, i.e., helping scholars develop their CS identity and sense of belonging in the profession AND recruiting K-12 students to PATHS (which is successful due to the interactions between the K-12 students and the diverse college students in PATHS).

\section{STRENGTHENING EXISTING PATHWAYS}

\subsection{Undergraduate Research}

While our original PATHS project did not purposely organize research experiences for undergraduates, several of the PATHS scholars have joined opportunities created by the CS@Mines faculty. For example, seven of the current PATHS scholars conduct robotics research in the CS@Mines MIRROR lab. In addition, two students worked on a NASA coding project in Python for the International Space Station. These types of experiences are empowering and motivating, e.g., all these students are doing quite well in their studies. The authors of [7] found that engaging undergraduate STEM students in research contributed to degree completion, retention, academic success, and professional development. Yang et al. [33] determined that students from underrepresented groups engaging in undergraduate research gained valuable research skills and became more engaged and motivated studying real-world problems. Undergraduate research is also another opportunity for students to develop a sense of support, belonging, and identity as STEM professionals $[4,22]$. At our annual summer retreat, we now ensure that all students are aware of the opportunity to engage in undergraduate research (e.g., Mines faulty presented undergraduate research opportunities in the Human Computer Interaction field at the 2020 zoom retreat).

One parent shared she was grateful for the PATHS financial and other support, including research, for her gifted and talented son. She wrote, "I wanted to also highlight how grateful we are for the focus School of Mines has put on opening the doors to undergraduate research - especially combined with the Engineering Grand Challenges. This focus was one of the reasons that [her son] chose to attend Mines and he was excited to make the early connection with Professor Williams to begin a long-term relationship before school even began. 


\subsection{Required College Transition Course}

All incoming first year students are required to take a college transition course. We created a PATHS cohort section of this course three years ago, which sometimes includes other non-PATHS students who are first-generation (first gen) students. PATHS scholars who are first semester transfer students are also required to attend our PATHS section of this course, with an option to audit the course. The PI of PATHS, herself a first gen student, usually teaches the course with two undergraduate peer mentors (both of whom are also first gen).

\subsection{Academic and Career Counseling}

PATHS students are required to meet at least once a semester with a faculty advisor. Mid-semester check-ins provide a platform for monitoring academic progress and sharing guidance about resumes, internships, campus opportunities, and career trajectories. Additionally, group meetings featuring informal talks with research faculty and career topics, such as negotiating salaries, are held over lunch (with pizza!) solely for PATHS scholars. According to the PATHS external evaluator, knowledge of CS career pathways increased during the 2019-20 school year. For example, PATHS students gained knowledge about career resources at Mines (the percent of students who stated 'knowledgeable about career services at Mines changed from 55\% to $81 \%$ ). Students reported similar growth in understanding career options within computing (students who stated 'knowledgeable about career paths changed from $55 \%$ to $88 \%$ ). Students who were new to PATHS had even stronger gains in knowledge and awareness of CS career paths (i.e., 0.69 increase for new scholars versus 0.25 increase for continuing scholars on a 5-point scale). Considering that only $25 \%$ of PATHS scholars' parents had a job related to computing/STEM and $62 \%$ of their parents only earned an associates degree or less, academic and career counseling is an essential support [32].

\section{PATHS SUPPORTIVE ECOSYSTEM}

\subsection{PATHS Community}

PATHS community support is available from peers, faculty, and staff. As mentioned, PATHS is organized as a cohort model. Cohort models are proven approaches for increasing retention and graduation rates [16, 31]. For example, one study showed that graduation rates were $90 \%$ higher for a cohort of 10 students when compared to similar students not in a cohort [6]. The collaborative aspect of STEM and CS projects naturally creates opportunities for social interactions, an important factor in creating identity [3]. The extent to which college students identify with their future career STEM identity can be predicted by the amount of social support they receive $[5,21]$. In addition, cohorts and social community support systems increase the likelihood of Latinx STEM retention [8,23], e.g., a simple $1 \%$ Latinx representation increase in STEM subfields led to increased retention of Latinx students [23]. The following activities illuminate how PATHS is a dynamic expanding community of students wrapped in peer-focused research-based supports from high school recruitment to college graduation.

\subsection{Peer Mentoring}

Soon after the formation of a new cohort, we match current scholars as mentors to incoming scholars, working to sync similar interests, backgrounds, etc. Mentor/mentee bonding was evident during the required PATHS Retreat in August 2019. Scholar mentors noted how they engage their mentees, meeting for coffee, emailing to share advice on classes, and encouraging participation in campus activities. In summer 2020, we created mentoring "groups" that include "grandparent" mentors. For example, a group might have a junior from cohort1, who is mentoring a sophomore from cohort2, who is mentoring a first year student from the most recent cohort. The PATHS program manager matches mentors and mentees based on similar characteristics. Both mentors and mentees are coached to co-create a working relationship that is respectful and supportive. While scholars determine the nature and frequency of mentor meetings, they are encouraged to meet monthly.

\subsection{Student-led Community Building}

PATHS community building and support activities work well when led by staff and faculty but are more empowering when led by students. With guidance from PATHS staff/faculty, committees of 2019-20 scholars began leading and organizing group events (e.g., the annual retreat, the scholarship application reviews, community dinners, and the peer mentor program). Scholars chose in 2019-20 to have an egalitarian non-formal structure rather than officers because they wanted everyone to feel equally valued, i.e., "no one is better than anyone else." See Figure 1 for a more complete list of PATHS activities.

\subsection{Students Attend Professional Conferences}

Sending PATHS scholars to national and regional diversity-focused conferences can be empowering for students who are underrepresented. In Fall 2018, PATHS sent three students to the Rocky Mountain Celebration of Women in Computing (RMCWiC) and, in Fall 2019, PATHS sent four students to the Richard Tapia Celebration of Diversity in Computing. Our PATHS scholars met other people like themselves, which likely increased their (1) identities as computer scientists and (2) sense of professional belonging [17]. Belonging, or a sense of being included, valued, and accepted as a legitimate member, has also been found to be a predictor of academic success and achievement [1].

\subsection{Student Selection Process}

Current PATHS scholars participate in choosing future PATHS cohorts. Current scholars evaluate anonymous scholarship applications using a formal rubric and discussion guidelines. Prior to the evaluation of applications, PATHS scholars attend professional development training on implicit bias and are asked to achieve a consensus score in small groups. After completion of their individual scoring, the team members deliberate to reach consensus on a ranking of all candidates, which is based on pre-set quantitative and qualitative factors.

In an open-ended question, all PATHS scholars found the application selection to be beneficial to their professional development. Scholars reported that they liked getting to know the candidates through their applications and that the process led to the selection 
of high-quality candidates. Students also learned what helps an application stand out and gained insight into and a strong connection with the PATHS program from the selection process. PATHS scholars (100\%) found the review of applications for incoming scholars "valuable" or "very valuable", solidifying the PATHS community and providing professional insight into the academic selection process. PATHS faculty and staff then make final scholarship decisions for eligible students, using the ranking of the applications from current scholar evaluations and consideration of other relevant criteria.

\subsection{Off Campus Summer Retreat}

Finally, the annual PATHS retreat is an important event that facilitates the development of community. The 2018 retreat was held in Keystone and the 2019 retreat was held in Winter Park, both of which are mountain towns an hour's drive west of Mines. Returning scholars help to develop retreat activities to ensure they are of direct interest and benefit to all attending scholars. The agenda always has a mix of team-building activities and introspective learning opportunities. The 2018 and 2019 in person retreats spanned a weekend in August before the fall semester. With our goal to foster family involvement where possible, the retreats began with an on-campus kick-off luncheon for scholars and families, at which the PATHS faculty and staff met parents and siblings in attendance. The PATHS PI gave introductory remarks about PATHS and the overall CS@Mines community. The students and PATHS leaders then headed to the mountains for an overnight.

The 2019 retreat received high marks from surveyed PATHS scholars. Survey responses also revealed that no one aspect of the 2019 retreat was most popular. At least two to four scholars reported enjoying each of the following activities: icebreakers, free time, photo scavenger hunt, values and belief-identifying activities, and Python coding. In other words, the retreat had something appealing to all scholars. An interactive workshop was presented by the Center for Academic Services and Advising (specifically presented by a CASA team member who is of Hispanic descent and also a first generation college student). This workshop was entitled "What's Your Why" and focused on students' goals, the value of teamwork, and how to use available resources optimally toward college success. His words resonated strongly with incoming scholars. In a photo scavenger hunt, students were randomly grouped into a team of four and given several ambiguous themes for photos. After dinner on the first evening, teams shared power point presentations of their photos resulting in some hearty laughter and many smiles. Returning scholars offered to participate in updating and improving the PATHS website and fostering PATHS Twitter and Instagram accounts. Overall the entire 2019 retreat agenda received high marks from surveyed participants.

The 2020 retreat was to be held at another mountain location but, unfortunately, had to be held via Zoom due to the health crisis. Nonetheless, students on the 2020 retreat planning committee devised a series of informational breakout room sessions for mentors and mentees, a "Pictionary" type game using the virtual whiteboard as an ice-breaker, and several other community building activities. All scholars who attended the Zoom retreat, which was held for four hours a day on the first Saturday and Sunday in August, reported they found the peer mentor meetings very helpful or helpful.
A returning Scholar shared, "I think that meeting with my mentee was the most useful and informative portion of the retreat this year. I also really enjoyed getting to meet with the returning scholars as I haven't talked to them all in one place since before the campus was shut down due to the virus." A full analysis of the August 2020 PATHS retreat is on-going.

\section{DISCUSSION}

Even with academic talent, low-income students often lack the guidance and support they need to prepare for, apply to, enroll in, and, ultimately, persist in college. Cultural, social, and financial challenges impose additional burdens on low-income undergraduates. Although there was an increase of low-income underrepresented students enrolling in college between 2010 to 2017, fewer students from these groups than white students from higher socioeconomic groups actually graduated [11]. By age 25, students from high income groups are six times more likely to earn a bachelor's degree than low-income peers. Only $30 \%$ of low-income students enroll in college; whereas, $80 \%$ of high-income students enroll in college.

PATHS provides a successful model for recruiting, retaining, and supporting academic and career pathways for low-income diverse undergraduates majoring or minoring in CS. Sax et al. [24-26] and Strayhorn [27] determined that having a sense of belonging is important for underrepresented students and a predictor of both general and CS academic success. Strayhorn and Longden et al. [14] attribute the importance of belonging in college success to Bourdieu's social capital theory and Tinto's interactionist theory. Programs like PATHS provide personal and community social capital as well as guidance about the pathways necessary to navigate college successfully (e.g., FAFSA forms and financial aid, registration, networking, obtaining letters of recommendation, applying for professional internships, and interviewing for technical positions). The ecosystem PATHS provides supports students in developing social capital among peers, staff, faculty, and industry contacts.

The PATHS program provides financial support as well, which is vital for college success of low-income students, i.e., Braxton [2] notes Bourdieu and Tinto's theories fail to address economic factors necessary for college success. In addition, PATHS has accountability, i.e., PATHS scholars must maintain a 2.75 GPA and participate in the ecosystem that exists. PATHS scholars report their academic progress twice a semester and work proactively with an advisor if they fall below the required 2.75. In summary, scholars engage in multiple aspects of developing personal, academic, social, and financial capital through PATHS.

\section{CONCLUSION}

PATHS (Path Ambassadors to High Success) is a successful NSFfunded S-STEM scholarship program for academically talented, low-income Colorado high school and community college students to study CS at Mines. Success factors of the program include: high retention rate (93.9\%), strong academic success (e.g., average GPA is 3.4), graduation rates, and successful employment in CS careers. The PATHS scholarships and program supports positively impact low-income, first generation, and underrepresented students. The PATHS ecosystem is a model that could benefit low-income students at other universities and colleges. 


\section{ACKNOWLEDGMENTS}

CS@Mines is grateful for the support from Jill Robertson and Sham Tzegai in the Mines Financial Aid office, Kyle Castro and Nicole Vilegi-Sandage in the Mines Admissions office, and Sharon Naylor, who provided intensive proactive academic mentoring for PATHS students who needed it. In addition, Dr. Tom Williams has been instrumental in providing undergraduate research opportunities and community games, as well as student mentoring. We also thank the parents, friends, teachers, and families of the PATHS scholars for providing their support. This material is based upon work supported by the National Science Foundation under Grant No. 1644198.

\section{REFERENCES}

[1] Jennifer M Blaney, Linda J Sax, David Feldon, and Ann Gates. 2019. Broadening participation in computing: Putting our work in context. In Proceedings of the 50th ACM Technical Symposium on Computer Science Education (SIGCSE). 490-491.

[2] John M Braxton. 2000. Reworking the student departure puzzle. Vanderbilt University Press.

[3] Heidi B Carlone and Angela Johnson. 2007. Understanding the science experiences of successful women of color: Science identity as an analytic lens. Fournal of Research in Science Teaching: The Official Journal of the National Association for Research in Science Teaching 44, 8 (2007), 1187-1218.

[4] Anthony Carpi, Darcy M Ronan, Heather M Falconer, and Nathan H Lents. 2017 Cultivating minority scientists: Undergraduate research increases self-efficacy and career ambitions for underrepresented students in STEM. fournal of Research in Science Teaching 54, 2 (2017), 169-194.

[5] Mitchell J Chang, Jessica Sharkness, Sylvia Hurtado, and Christopher B Newman 2014. What matters in college for retaining aspiring scientists and engineers from underrepresented racial groups. Journal of Research in Science Teaching 51, 5 (2014), 555-580.

[6] Salvador Contreras, Frank Badua, Jiun Shiu Chen, and Mitchell Adrian. 2011 Documenting and explaining Major Field Test results among undergraduate students. Fournal of Education for Business 86, 2 (2011), 64-70.

[7] Melissa B Crawford, Zakiya S Wilson-Kennedy, Gloria A Thomas, Samuel D Gilman, and Isiah M Warner. 2018. LA-STEM Research Scholars Program: A model for broadening diversity in STEM education. Technology \& Innovation 19 , 3 (2018), 577-592.

[8] Melissa Dagley, Michael Georgiopoulos, Amber Reece, and Cynthia Young. 2016 Increasing retention and graduation rates through a STEM learning community. Journal of College Student Retention: Research, Theory \& Practice 18, 2 (2016), 167-182.

[9] Peggy Doerschuk, Cristian Bahrim, Jennifer Daniel, Joseph Kruger, Judith Mann, and Christopher Martin. 2014. An award winning program for increasing participation in STEM. In Proceedings of the 2014 IEEE Frontiers in Education Conference (FIE). IEEE, 1-8

[10] Mica Estrada, Paul R Hernandez, and P Wesley Schultz. 2018. A longitudinal study of how quality mentorship and research experience integrate underrepresented minorities into STEM careers. CBE-Life Sciences Education 17, 1 (2018), ar9.

[11] Sara Goldrick-Rab, Robert Kelchen, Douglas N Harris, and James Benson. 2016. Reducing income inequality in educational attainment: Experimental evidence on the impact of financial aid on college completion. American fournal of Sociology 121, 6 (2016), 1762-1817.

[12] Daniel Heersink and Barbara M Moskal. 2010. Measuring high school students' attitudes toward computing. In Proceedings of the 41st ACM Technical Symposium on Computer Science Education (SIGCSE). 446-450.

[13] Parag Kanna and Karan Khemka. 2020. The Coronavirus butterfly effect: Six predictions for a new world order. https:/www.fastcompany.com/90488665/the- coronavirus-butterfly-effect-six-predictions-for-a-new-world-order Accessed: 2020-04-14.

[14] Bernard Longden. 2004. Interpreting student early departure from higher education through the lens of cultural capital. Tertiary Education \& Management 10, 2 (2004), 121-138.

[15] Jane Margolis and Allan Fisher. 2003. Unlocking the clubhouse: Women in computing. MIT press.

[16] Sathya Narayanan, Kathryn Cunningham, Sonia Arteaga, William J Welch, Leslie Maxwell, Zechariah Chawinga, and Bude Su. 2018. Upward mobility for underrepresented students: a model for a cohort-based bachelor's degree in computer science. In Proceedings of the 49th ACM Technical Symposium on Computer Science Education (SIGCSE). 705-710.

[17] Christopher B Newman. 2016. Minority engineering programs at a crossroads. Fournal for Multicultural Education 10, 2 (2016), 217-233.

[18] NSF. [n. d.]. National Science Foundation: Broadening Participation in Computer Alliance Program. https://www.nsf.gov/nsb/sei/edTool/data/workforce-03.html. Accessed: 2020-11-27.

[19] NSF. [n. d.]. National Science Foundation: Broadening Participation in Computing (BPC). https://www.nsf.gov/cise/bpc/. Accessed: 2020-11-23.

[20] Carlos Oliveira. 2016. The importance of learning computer programming for engineers. In Proceedings of the International Conference on Industrial Engineering and Operations Management. 2311-2314.

[21] Becky Wai-Ling Packard and Dam Nguyen. 2003. Science career-related possible selves of adolescent girls: A longitudinal study. Fournal of Career Development 29, 4 (2003), 251-263.

[22] Aneeta Rattan, Krishna Savani, Meera Komarraju, Megan M Morrison, Carol Boggs, and Nalini Ambady. 2018. Meta-lay theories of scientific potential drive underrepresented students' sense of belonging to science, technology, engineering, and mathematics (STEM). Journal of Personality and Social Psychology 115, 1 (2018), 54.

[23] Blanca E Rincón. 2018. Does Latinx representation matter for Latinx student retention in STEM? Journal of Hispanic Higher Education 19, 4 (2018), 434-451.

[24] Linda J Sax, Kathleen J Lehman, and Christina Zavala. 2017. Examining the enrollment growth: Non-cs majors in CS1 courses. In Proceedings of the 48th ACM Technical Symposium on Computer Science Education (SIGCSE). 513-518.

[25] Linda J Sax, Casey A Shapiro, and M Kevin Eagan. 2011. Promoting mathematical and computer self-concept among female college students: Is there a role of single-sex secondary education? Journal of Women and Minorities in Science and Engineering 17, 4 (2011), 325-355.

[26] Linda J Sax, Hilary B Zimmerman, Jennifer M Blaney, Brit Toven-Lindsey, and Kathleen Lehman. 2017. Diversifying undergraduate computer science: The role of department chairs in promoting gender and racial diversity. Journal of Women and Minorities in Science and Engineering 23, 2 (2017), 101-119.

[27] Terrell L Strayhorn, Fei Bie, Marjorie L Dorime-Williams, and Michael Steven Williams. 2016. Measuring the influence of Native American college students' interactions with diverse others on sense of belonging. Journal of American Indian Education 55, 1 (2016), 49-73.

[28] Heather Thiry. 2019. External Evaluation of the PATHS Scholarship Program at Colorado School of Mines, 2018-2019.

[29] Heather Thiry. 2020. External Evaluation of the PATHS Scholarship Program at Colorado School of Mines, 2019-2020.

[30] Yong Wang, Kasey J Hill, and Erin C Foley. 2017. Computer programming with Python for industrial and systems engineers: Perspectives from an instructor and students. Computer Applications in Engineering Education 25, 5 (2017), 800-811.

[31] Linda Wild and Larry Ebbers. 2002. Rethinking student retention in community colleges. Community College fournal of Research and Practice 26, 6 (2002), 503519

[32] Heather Wright and Burcin Tamer. 2019. Path Ambassadors to High Success (PATHS): Comparative evaluation of pilot and Cohort 1 to a national sample.

[33] Guang-Zhong Yang, Bradley J Nelson, Robin R Murphy, Howie Choset, Henrik Christensen, Steven H Collins, Paolo Dario, Ken Goldberg, Koji Ikuta, Neil Jacobstein, et al. 2020. Combating COVID-19-The role of robotics in managing public health and infectious diseases. Science Robotics 5, 40 (2020). 